\title{
Hans-Georg Gadamer's philosophical hermeneutics and journalism research
}

\author{
Donald Matheson
}

The philosophical hermeneutics of German phenomenologist Hans-Georg Gadamer (1900-2002) is rarely cited in journalism studies, although it is better known in the fields of history, literary study and classical philology. I would like to suggest here that journalism studies can make fruitful use of the philosophical concepts he developed, in particular to use those idea to bring journalism's interpretative work to the fore in critical enquiry. In the course of introducing some of his ideas, I emphasise implications for studying the practical knowledge of the journalist, the dichotomy between objective and subjective reporting, and neglected aspects of journalism ethics.

One of the rallying cries of journalism studies is that the journalists' practice cannot be adequately critiqued without an understanding of its practitioners' perspectives. However, integrating the views of journalists into a theory of journalism is difficult, not least because of a general lack of enthusiasm among even reflective journalists to revise their profession's epistemological claims. As former Chicago Tribune editor and publisher Jack Fuller notes, the suspicion of theory means 'that some of the most restless and interesting journalists have had trouble making any claim to truth at all' (Fuller 1996: 5). Yet to fill this gap in self-theorising by treating the way journalism knows the world as a sub-set of other forms of knowledge - enduring narratives (Lule 2001), for example, or dominant ideologies - is rather reductive, for there is a widespread ethical commitment among journalists to notions such as 'telling it like it is' and 'telling truth to power'. It is, then, difficult to pin down the knowledge production practices of journalism.

This paper suggests that the conceptual problem can be eased by drawing upon alternative ways of thinking about knowledge which might have greater purchase upon journalism practice. Hans-Georg Gadamer's philosophical hermeneutics, which was in the broadest sense an attempt to revalue the forms of knowledge of the 
humanities (Geisteswissenschaften) against the dominance of scientific knowledges, may provide some help. Gadamer rejected the dominance of scientific epistemologies, including the dichotomy between objective knowledge and lived experience, which had marginalised that which did not fit, such as art, to merely aesthetic or private value. Following his mentor Heidegger's lead, he thought of the human condition as fundamentally one of ontological insecurity: we are born with no certainties other than that we will die. In that state, the drive to understand is a basic aspect of being alive, a state that leads not to final knowledge but to constant revision of understanding. As one interpreter of Gadamer puts it, 'We strive to understand because, at a basic level, we do not fully understand at all' (Grondin 1999: 224). In Gadamer's thinking, understanding becomes inseparable from being, a matter of being awake to what is out 'there' beyond ourselves. 'To have knowledge, in this sense,' Grondin writes elsewhere, 'is less to have knowledge of this or that, with the goal of mastery which remains objectivizing, but to be there, "in" the meaning which challenges us' (Grondin 2003: 96).

This sensitivity to the irreducible thereness and nowness of the world for us, as well as the wide-awake quality of the good observer of the world, finds echoes in journalism. Yet these are qualities that are easily neglected in journalism critique which lets itself be framed by the practice's scientistic language of objectivity, mirroring the world and verification. As I was preparing this paper, BBC radio broadcast a report by its Middle East correspondent, Tim Franks, that illustrates what can be left out in such a critical frame. The story, a colour piece about the plight of two prominent Iraqi Jewish musicians who fled to Israel in 1951, only to be relegated to playing at bar mitzvahs in Tel Aviv while they were erased from the national culture at home, was rich in material about the inter-ethnic prejudice fanned by the post-war rise of racialising nationalism in both countries (Franks 2009). While the news hook for discussing the al-Kuwaiti brothers was controversy over the decision to rename a street after them, the story's news value was clearly about the enormous task of reconciliation in the region. Yet that was nowhere made explicit by the reporter there is no statement in the text of what this family’s story means. Instead, Franks gives finely observed detail about the family, and allows the material, in a common journalistic manoeuvre, to resonate with wider significance. How Franks knows this material, and what meanings about Israel he is privileging in his account, remain 
somewhat opaque. He could be accused of failing to verify his facts or attribute these meanings to various sides of the issue - that is, of failing to signal his position outside any ideological position.

I was, however, struck by the power of the simple story and would argue that the journalist's work here needs to be partly revalued. Instead of emphasising how the journalist knows the world, there is value in also asking how a world comes to view through the reporter's work. Franks' piece can be re-read, then, as recounting some of the experience of the foreign correspondent as he sees particular tensions unfold before him. In drawing upon this common form of reportage, the correspondent invites the listener to experience those same facts. The lack of overt interpretation allows the listener to encounter these people less as symbols of something larger or as instances of a wider narrative, than as specific people in a concrete world. In the encounter, an interpretative space is opened up in which wider questions about Israel's fraught identity and position become available. The questions specific listeners ask are likely to be different - as the widely varying comments from British, Saudis, Israelis and others on the BBC story's online version attest. In other words, an approach that looks for the ontological grounds of meaning-making can augment our theoretical resources for understanding journalists' encounters with the world and their textual practices.

Discussing these ideas is all the more relevant because forms of journalism which work in modes outside the 'he said-she said' genres of ostensibly objective hard news reporting are in the ascendant. Hannerz describes the rise of a 'cosmopolitan journalism' replacing the hard international news reporting of the Cold War, which he suggests works to develop among publics a 'feeling of being to some degree at home in the world' (Hannerz 2004: 33). Other observers note the centrality of liveness to television news since the 1990s, in which the experience of being at the scene of the news event eclipses packaged reports of what happened (PEJ 2005, Cottle 2006). Citizen journalism and other forms of amateur media enabled by digital media have burst onto the scene since about 2001, alongside a greater use within mainstream journalism of subjective forms, all of which invite the reader to experience some kind of co-presence with witnesses to public events (Allan 2006). As the sense of living in a mediated world has taken hold in contemporary society, many critics (e.g. Couldry 
2003, Ekström \& Johansson 2008) have begun to describe political journalism less as a messenger to the public than as a stage upon which political life is carried out before the public. Disparate though they are, common to these kinds of developments is a shift away from the 'high modernist', in Hallin's (1992) phrase, record of facts to more experiential and interpretative forms of reporting. In particular, Barnhurst and Mutz (1997) argue US journalism has undergone a long-term shift away from factual reporting of events towards accounts of responses to events. As others (e.g. Allan 2004: 210ff) have shown, accompanying these changes has been a growing dissatisfaction with theoretical accounts that regard these forms as of lesser quality or value.

\section{A two-minute introduction to Gadamer}

Gadamer's emphasis on the interconnectedness of the concepts of truth and understanding has, I argue, some value for the study of these aspects of journalistic knowledge which do not fit dominant modernising scientific models. The discussion below focuses on three aspects of his thinking: his restoration to prominence of Aristotle's notion of phronesis, or practical wisdom; the value he placed on interpretation as a form of truth-telling; and his emphasis on interpretation, listening and other aspects of hermeneutic engagement with the world as moral acts. Gadamer's value to theorists of journalism begins with his embrace of the idea of truth - a term that Zelizer (2004) reminds us is one of Anglo-American journalism's 'God-terms'. Indeed Gadamer's major work is called Truth and Method (Wahrheit und Methode) (1979). Yet truth is different here - it is not some empirically verifiable object. For Gadamer, truth emerges in fullness of understanding being made manifest, which he refers to somewhat enigmatically as the holding of what is said 'together with an infinity of what is not said in one unified meaning' (ibid: 469). Truth becomes, for many readers of Gadamer, a synonym for understanding at its best (e.g. Bain-Selbo 2002), in which the horizons of the interpreter and the interpreted are fused for a moment. Thinking of journalism as, at its best, a public fusing of horizons of understanding might enrich some of our normative theories.

To make sense of such statements, a brief account of Gadamer's theory of interpretation is needed. Following Heidegger, and in common with many other hermeneutic theorists, Gadamer proposes that understanding is circular. All 
understanding begins with prejudgements (Vorurteile, literally prejudices) by which the object is first grasped as something to be understood. Without such preconceptions, we would not be interested in engaging with an object and would not be able to comprehend it or anticipate its position within a larger idea or event. Following this, engagement with the object begins to have an impact upon us - our prejudgements may either be confirmed or challenged - which leads us to look upon the world in a slightly different light. As many commentators note, this circle of understanding is theorised not as a vicious one by which prejudice reinscribes itself, but as a necessary part of making sense in which we project fore-knowledge onto the world in order to begin to understand it. Ricoeur, beginning from the model of the sentence, argues that each word is interpreted in a circular movement between its own meaning and its meaning as part of the clause or sentence, which he terms 'the prior supposition of a certain kind of whole’ (Ricoeur 1981: 211, see also Edgar 1992: 113). For Gadamer, understanding at its best - which we might call 'true understanding' - involves a reflexivity, whereby prejudgements are always available to be challenged. Invoking the image of the horizon, he talks of the interpreter allowing her or his horizon to be changed by the encounter with the world. In a phrase he used repeatedly, to approach truth is to believe that the other may be right. He writes of 'recognizing in advance the possibility that your partner is right, even recognizing the possible superiority of your partner' (Gadamer 1997: 36, see also Wiercinski 2009).

The divergence from dominant scientific methods of approaching truth is significant. Gadamer accused science - although he acknowledged diversity within it - of an historic prejudice against prejudices, which carried the grave risk that it would be shaped by ignored prejudices. Thus, rather than separating the observer and the observed, his phenomenological approach sought to place the observer as part, for a moment, of the thing being understood. He talks at various points of 'participation in understanding', of the individual being 'in play' in a moment of understanding that extends between the individual and the object, in the same way as players lose their separateness when they are part of a game. In that moment of participation, the horizons of the interpreter and that which is being interpreted become fused, so that what the other 'truly means to me' becomes understood. 
In literary theory, Gadamer's writings have been used to theorise the relationship of author and reader/critic, allowing for a finer position between authorial authority over meaning and the rejection of that authority. While the reader's intention must always be to understand the text, that intention is necessarily shaped by the reader's position in the present. The reading is an experience of the text's meaning, emphasised Wolfgang Iser, a student of Gadamer's and the founder of reader-response theory (Iser 1978). Some analysts of media reception, such as Wilson and Thang (2007), have drawn upon Gadamer to explore how individuals project their own 'foreknowledge' onto media objects in their interaction with them (such as when using the web). Other media researchers, particularly in Nordic and German-speaking countries (e.g. Dahlgren 1980) have a long tradition of grounding textual analysis in a range of hermeneutic principles. In historical studies, Gadamer's focus on the 'betweenness' of the interpreter, not part of the historical object but at the same time connected to it through all that has already been said about it, has been influential. That is, the 'historical consciousness' of the historian is itself a product of the history being studied. Gadamer has also been widely cited in areas as diverse as game theory and the exegesis of religious texts, all in the context of shifting away from any sense of final interpretation, instead locating the deepest profundity of understanding in the experience of coming close to what others truly mean.

In the study of journalism, analysis of how journalists interpret has tended to be marginalised in favour of more epistemologically grounded questions of how journalists know what they know. Thus Ekström’s (2002) rich analysis of television journalism's ‘knowledge-producing practices' deals mostly with justifications, logics and rules that undergird journalism's sense of itself. Even phenomenologicallyinformed approaches to journalism practice, such as the classic ethnographies of Tuchman (1978) and Fishman (1980), tend to emphasise news practices, such as the casting of a 'news net' upon the world in order to comprehend it, and typifying as news only that which falls into the net, as techniques of knowing, rather than as modes of being. Indeed, in a logic that risks being a (vicious) circle, the identification of these journalistic techniques to manage newsgathering becomes a critique of the rigidity of newsgathering (a point I return to shortly). There is clearly room for a range of approaches, but Gadamer helps us ask what is missed when the journalistic understanding of the world is framed in these terms. 


\section{Holistic understanding and common sense}

Gadamer, in seeking to rehabilitate the humanities, draws upon Aristotle's notion of phronesis, or the practical knowledge of what is right that is embedded in action and daily life. Unlike theoretical knowledge of what is right or technical knowledge of how to achieve something, phronetic knowledge is envisaged not as a method or set of rules, but as a capacity, as something we do. As such, it includes both affective and instinctive responses. Gadamer cites Aristotle's example of archery, where rules of how to take aim must be supplemented by learning how to hold the bow and get a feel for the task (Gadamer 1979: 134). He himself uses the example of a judge, whose relationship to law is not one of knowing law in the abstract as much as doing it in the here and now. The law needs to be interpreted in terms of what it means for the present case being considered.

This kind of understanding is holistic; that is, like Ricoeur's reader of the sentence, it involves the individual engaging with the whole of his or her being with the whole of the object, in the present context. Edgar (1992), one of the few scholars to relate Gadamer's hermeneutics to journalism, gives the example of a hurricane story. When the journalist hears of a hurricane, his or her 'initial decision to attend to the event will rest upon the anticipation of the place of that event in a broader whole' (ibid: 117). In one dimension, that broader whole is the bigger category of storm events. In another, it is the journalistic category of weather stories, with their dramatic visuals and opportunities for live reporting. In another, it is the journalist's awareness of other stories happening at the time, which may or may not be regarded as more worthy of coverage. Edgar uses the point in his argument against the possibilities of any objective account of the hurricane. 'As with all interpretation, a news report does not grasp the event definitively, but within a given horizon' (ibid: 118). The example also suggests, however, that from the very first moment that the journalist encounters a possible story - in fact, in order for the journalist to encounter the 'occurrence' at all as a news 'event', in Tuchman's (1978) phrasing - a large array of preconceptions is deployed. Seeing is from the very first moment an act of understanding, or at least an anticipation of what the object being seen could mean. 
Seen in this light, the difficulties that journalists often have in justifying their news decisions in terms other than a 'nose for news' or a generalised sense of the public interest may be less a failure in self-knowledge, than a reliance upon a different kind of knowledge. To say this does not remove journalism from criticism for the dominance of certain forms of news, but it takes us closer to understanding how and why certain forms of news are reported so often. Glasser and Ettema (1989) make just this point, arguing that scholars need to pay closer attention to journalists' accounts of how novice reporters learn from the 'wisdom' of their seniors in recognising news stories within the stream of potential news. Drawing upon Geertz's description of common sense as practical, immethodical and natural, they argue that a similar knowledge exists among journalists of 'how a story can go'. Certain kinds of material can be recognised as capable of being transformed into certain types of story. What rubs off from experienced peers, Glasser and Ettema argue, is 'not so much the tricks of the trade or even an elder's proverbs but rather a style of thought - attuned not only to the profession's traditions and practices but to the heritage of one's culture' (ibid: 24). A hermeneutic account can go further, proposing that what novice journalists are developing is their version of the newsroom's horizon of understanding, a sense of the whole story or whole news practice in terms of which particular statements and events will make sense to them as news. The stories which journalists tell each other (Zelizer 1993) and the recognition of prior stories in new ones (Kitzinger 2000) are all part of this developing awareness of the world. A Gadamerian might also want to ask whether the newsroom environment is indeed as homogenising as the more structural accounts of news practice suggest (see Ericson et al. 1987: 26). Is it possible that the horizon of how a story can go is a more context- dependent, flexible thing than we are used to imagining?

\section{Beyond the subjective-objective split}

Gadamer places language at the heart of understanding. In one of his most famous statements, he proposes that, 'Being that can be understood is language' (Gadamer 1979: 432). All that part of experience which can be grasped between people - that is, understood - takes place in language. A world, a being here and now, becomes graspable when an individual places her or himself in relation to others through words. One of the major consequences of this thread of thinking is that neither the interpreter not the interpreted can be given theoretical priority. As already noted, 
Gadamer thinks of the interpreter as part of the meaning of what is being read, and rejects out of hand the notion of an objective knowledge. How, he asks, can it make sense to put ourselves in brackets if we wish to understand what is right? He talks in a number of places of understanding as a dialogue, in which any utterance is always a reply to a previous one, that is, it always presupposes previous statements and understandings, and always followed by a response. In both these images, the individual recedes from view. 'Those who take part in dialogue are not so much participants as those in whom the dialogue participates' (Gadamer 1979: 1). As Wright (1998) notes, Gadamer, in moving beyond objectivist accounts, carefully grounds understanding not in subjectivity but in language and dialogue.

This sense of a space between people builds usefully on other dialogic theories, such as Voloshinov's or Habermas's, which emphasise the relational as the basis of knowledge construction. What strikes me as distinctive and also of particular value in studying journalism practice is Gadamer's insistence on that space as the outcome of the interpreter's search for what the object of attention truly means to that interpreter, and his willingness to regard that outcome as a kind of truth. For, while objectivity has never achieved a particularly close fit with journalism, remaining something of a self-deception or at best an aspiration, as so many scholars have attested, the underlying ethical commitment expressed within journalism practice to a truth that is out there in the world, and that is more than the journalist's personal understanding, cannot be simply ignored. Journalism is a truth-telling discourse, however inadequate many of its own theoretical justifications are for that status. What Gadamer perhaps offers journalism, as much as journalism scholarship, is another way of describing the endeavour to approach truth. Gadamer imagines the 'rightness' of understanding as a momentary fusing of horizons, during which the object is allowed to speak to the observer, just as when the voice of the original author is allowed to speak in a good translation. Perhaps aspects of good journalism and aspects of a journalistic ideal can be described similarly: something of the truth of public events is heard when the reporter brings an array of facts and voices together for a moment in a way that allows a unity and coherence of meaning to be perceived, yet ready to revise or even contradict that account in the next report.

\section{Ethical interpretation}


Any hermeneutic theory that can be drawn out of Gadamer's writings must have a strong ethical valuation of understanding. Practical knowledge of the world is, for both Aristotle and Gadamer, an ethical endeavour, in which good ends are sought. Understanding is about a fullness of interpretation, a moment of being which approaches what the other truly means to one. Truth and understanding are intimately interconnected in his account. Consequently, to bring the interpretative spaces constructed in journalism to light is to begin to discuss an important aspect of its ethics.

Of particular value to journalism ethics is the idea of good or true interpretation. Unlike Habermas, who looks to pragmatics to help him identify conditions for quality public debate, Gadamer avoids what he sees as techniques of truth-telling. Grondin (2003) spends considerable time in his analysis of Gadamer arguing that what is envisaged is a state of being in truth rather than a way of knowing truth. Without reducing the approach to a method, some points can be made, however, about how this state emerges. I discuss these in more detail elsewhere (Matheson 2004), but in outline Gadamer asks interpreters to listen and to be 'vigilant'. Listening - as aspect of journalism practice which again is rarely investigated - stands as the polar opposite of what Ricoeur (1970) termed the 'hermeneutics of suspicion', where a critical agenda drives interpretation. That is, listening directs us to consider, as noted above, that the other may be right. Vigilance entails a 'confrontation with ourselves' (Grondin 2003: 49), so that we hold in mind the preconceptions through which understanding begins. Edgar uses hermeneutic theory to propose that the journalist's interpretation of reality 'must remain genuinely open to the questions that other actors can pose to it' (1992: 128).

Gadamer's point goes further, however. Understanding, as a linguistic action in a here and now, is always going to belong to that instance of being. There is no simple progression towards better understanding through repetitions of the hermeneutic circle. Instead, he wants to recognise the limits of our capacities and to acknowledge the value of always trying anew. There is then an appreciation of limitation, of a humility, in understanding. He would not only want journalists to reflect on their own prejudgements, but also ask them to qualify what they know, making clear the 
temporality and the situatedness of their knowledge, all the while continuing to hold tight to a desire to grasp the object in its wholeness.

\section{Concluding thoughts}

There is no space here to discuss critiques of Gadamer or his dialogues with other contemporary theorists other than to briefly qualify the points I have made.

Gadamer's thinking provides, firstly, no grand theory of public debate. Instead, like many language philosophers, he begins from the interpersonal, as well as from the experience of art or God. Practices such as journalism which speak for those whom they also speak to do not always fit neatly within philosophical hermeneutics - the question of how individuals, publics, journalists and those represented in the news are all at play in the moment of the news is difficult to resolve. Gadamer also has little to say on one of the most important questions around public debate - the role of power. Ricoeur, for example, argues for the need to balance the kind of hermeneutics of respect for the other which Gadamer outlines, with a more critical hermeneutics of suspicion (Cefaï \& Munoz-Dardé 1999). Habermas finds in Gadamer’s writings only a weak critique of the forces of dominance which organise the objects of understanding. Particularly in a contemporary cultural context where horizons are being fused in western capitalism's global expansion, we might want to value difference and acts of resistance more strongly (see Pickering 1997: 156-7).

However, there is much here of value to journalism studies. Gadamer provides ways of talking about - and thereby opening up for study - aspects of the practice which eludes more epistemologically concerned theories. Journalistic nous, such as the knowledge embedded in Tim Franks' use of significant detail to illuminate a political issue, discussed above, need not be seen as inadequate or pre-theoretical knowledge, but as part of the horizon which is shared within a certain journalistic community allowing them to see material as possible news. Similarly, the news judgement here, which Franks might well struggle to articulate except in terms of a 'powerful story', can be valued precisely for its holism, which allows the details of the al-Kuwaiti family to remain details, and not be reduced to instances of a bigger story. Work on the phenomenology of broadcasting (e.g. Scannell 1996) can be connected with analysis of how journalists open up interpretative spaces at moments such as this, where the BBC's listeners could feel some of the fraught identity of Israel. 
Conversely, the journalistic concern for truth can be disconnected from unrealistic notions of objectivity, valuing the correspondent's attempt to encounter the true experience of the people in the story. Running through all these points is an ethical agenda, providing ways to talk about the good and the true in journalism's interpretative work, that is, to judge whether journalists such as Franks are truly listening to the other or opening up spaces where horizons of understanding may meet for a moment. 


\section{References}

ALLAN, STUART (2004) News Culture, Maidenhead: Open University Press.

ALLAN, STUART (2006) Online News: Journalism and the Internet, Maidenhead: Open University Press.

BAIN-SELBO, ERIC (2002) Mediating the Culture Wars, Cresskill, NJ: Hampton Press.

BARNHURST, KEVIN and DIANA MUTZ (1997) "American Journalism and the Decline in Event-Centered Reporting", Journal of Communication 47(4), pp. 27-53.

CEFAÏ, DANIEL and VÉRONIQUE MUNOZ-DARDÉ (1999) "Social and Moral Understanding: Ricoeur", SIMON GLENDINNING (Ed.), The Edinburgh Encyclopedia of Continental Philosophy, Edinburgh: Edinburgh University Press, pp. 231-38.

COTTLE, SIMON (2006) Mediatized Conflict, Maidenhead and New York: Open University Press.

COULDRY, NICK (2003) Media Rituals: A Critical Approach, London: Routledge.

DAHLGREN, PETER (1980) "TV News and the Suppression of Reflexivity", Urban Life 9, pp. 201-16.

EDGAR, ANDREW (1992) "Objectivity, Bias and Truth", RUTH F. CHADWICK and ANDREW BELSEY (Eds), Ethical Issues in Journalism and the Media, London: Routledge, pp. 112-29.

EKSTRÖM, MATS (2002) "Epistemologies of TV Journalism", Journalism 3, pp. 259-82.

EKSTRÖM, MATS and BENGT JOHANSSON (2008) "Talk Scandals", Media, Culture \& Society 30(1), pp. 61-79.

ERICSON, RICHARD V., PATRICIA M. BARANEK and JANET B.L. CHAN (1987) Visualizing Deviance: A Study of News Organizations, Milton Keynes: Open University Press.

FISHMAN, MARK (1980) Manufacturing the News, Austin: University of Texas Press.

FRANKS, TIM (2009) "Jerusalem Diary: 2 March", BBC News, 2 March. http://news.bbc.co.uk/2/hi/middle_east/7918339.stm, accessed 2 April, 2009.

FULLER, JACK (1996) News Values: Ideas for an Information Age, Chicago: University of Chicago Press.

GADAMER, HANS-GEORG (1979) Truth and Method, London: Sheed and Ward.

GADAMER, HANS-GEORG (1997) "Reflections on My Philosophical Journey", LEWIS E. HAHN (Ed.), The Philosophy of Hans-Georg Gadamer, Chicago: Open Court, pp. 3-63.

GLASSER, THEODORE L. and JAMES S. ETTEMA (1989) "Common Sense and the Education of Young Journalists", Journalism Educator 44(2), pp. 18-25, 75.

GRONDIN, JEAN (1999) "Understanding as Dialogue: Gadamer", SIMON GLENDINNING (Ed.), The Edinburgh Encyclopedia of Continental Philosophy, Edinburgh: Edinburgh University Press, pp. 222-30.

GRONDIN, JEAN (2003) The Philosophy of Gadamer, Montreal: McGill-Queen's University Press. 
HALLIN, DANIEL (1992) "The Passing of the 'High Modernism' of American Journalism", Journal of Communication 42, pp. 14-25.

HANNERZ, ULF (2004) Foreign News: Exploring the World of Foreign Correspondents, Chicago \& London: University of Chicago Press.

ISER, WOLFGANG (1978) The Act of Reading: A Theory of Aesthetic Response, Baltimore: Johns Hopkins University Press.

KITZINGER, JENNY (2000) "Media Templates: Patterns of Association and the (Re)Construction of Meaning over Time", Media Culture \& Society 22, pp. 61-84.

LULE, JACK (2001) Daily News, Eternal Stories: The Mythological Role of

Journalism, New York: Guilford Press.

MATHESON, DONALD (2004) "Journalists as Interpreters: Gadamer and Elements of a Communicative Ethics in News Culture", Ethical Space 1(2), pp. 37-43.

PEJ (2005) "Cable TV: The State of the News Media: An Annual Report on American Journalism". http://www.stateofthenewsmedia.com/2004/, accessed 223 August, 2006.

PICKERING, MICHAEL (1997) History, Experience and Cultural Studies, Basingstoke: Macmillan.

RICOEUR, PAUL (1970) Freud and Philosophy: An Essay on Interpretation, New Haven: Yale University Press.

RICOEUR, PAUL (1981) Hermeneutics and the Human Sciences: Essays on Language, Action and Interpretation, Cambridge: Cambridge University Press.

SCANNELL, PADDY (1996) Radio, Television, and Modern Life: A Phenomenological Approach, Cambridge: Blackwell.

TUCHMAN, GAYE (1978) Making News: A Study in the Construction of Reality, New York: The Free Press.

WIERCINSKI, ANDRZEJ (2009) "Hans-Georg Gadamer and the Truth of Hermeneutic Experience", Analecta Hermeneutica 1, pp. 3-12.

WILSON, TONY and FLORENCE THANG (2007) "The Hermeneutic Circle of Cellphone Use: Four Universal Moments in a Malaysian Narrative of Continuing Contact", New Media \& Society 9, pp. 945-63.

WRIGHT, KATHLEEN (1998) "Gadamer, Hans-Georg", EDWARD CRAIG (Ed.), Routledge Encyclopedia of Philosophy, London: Routledge, pp. 827-31.

ZELIZER, BARBIE (1993) "Journalists as Interpretive Communities", Critical Studies in Mass Communication 10, pp. 219-37.

ZELIZER, BARBIE (2004) "When Facts, Truth, and Reality Are God-Terms: On Journalism's Uneasy Place in Cultural Studies", Communication and Critical/Cultural Studies 1(1), pp. 100-19.

Donald Matheson, Media and Communication Programme, University of Canterbury, Private Bag 4800, Christchurch, Aotearoa/New Zealand. Email:

donald.matheson@canterbury.ac.nz. 